\title{
Age-based disparities in end-of-life decisions in Belgium: a population-based death certificate survey
}

Kenneth Chambaere ${ }^{1 *}$, Judith A C Rietjens ${ }^{1}$, Tinne Smets ${ }^{1}$, Johan Bilsen ${ }^{1}$, Reginald Deschepper ${ }^{1}$, H Roeline W Pasman ${ }^{2}$ and Luc Deliens ${ }^{1,2}$

\begin{abstract}
Background: A growing body of scientific research is suggesting that end-of-life care and decision making may differ between age groups and that elderly patients may be the most vulnerable to exclusion of due care at the end of life. This study investigates age-related disparities in the rate of end-of-life decisions with a possible or certain life shortening effect (ELDs) and in the preceding decision making process in Flanders, Belgium in 2007, where euthanasia was legalised in 2002. Comparing with data from an identical survey in 1998 we also study the plausibility of the 'slippery slope' hypothesis which predicts a rise in the rate of administration of life ending drugs without patient request, especially among elderly patients, in countries where euthanasia is legal.
\end{abstract}

Method: We performed a post-mortem survey among physicians certifying a large representative sample $(n=6927)$ of death certificates in 2007, identical to a 1998 survey. Response rate was 58.4\%.

Results: While the rates of non-treatment decisions (NTD) and administration of life ending drugs without explicit request (LAWER) did not differ between age groups, the use of intensified alleviation of pain and symptoms (APS) and euthanasia/assisted suicide (EAS), as well as the proportion of euthanasia requests granted, was bivariately and negatively associated with patient age. Multivariate analysis showed no significant effects of age on ELD rates. Older patients were less often included in decision making for APS and more often deemed lacking in capacity than were younger patients. Comparison with 1998 showed a decrease in the rate of LAWER in all age groups except in the $80+$ age group where the rate was stagnant.

Conclusion: Age is not a determining factor in the rate of end-of-life decisions, but is in decision making as patient inclusion rates decrease with old age. Our results suggest there is a need to focus advance care planning initiatives on elderly patients. The slippery slope hypothesis cannot be confirmed either in general or among older people, as since the euthanasia law fewer LAWER cases were found.

Keywords: Ageism, Age inequalities, End of life, End-of-life decisions, Slippery slope, Euthanasia, Palliative care, Belgium

\footnotetext{
* Correspondence: kenneth.chambaere@vub.ac.be

'End-of-life Care Research Group, Ghent University \& Vrije Universiteit Brussel, Laarbeeklaan 103, Brussels 1090, Belgium

Full list of author information is available at the end of the article
} 


\section{Background}

Life expectancy in developed countries has risen considerably during the last century [1,2]. This has had a profound impact on the age distribution of populations: the number and proportion of elderly people is steadily rising and is projected to increase further. The "baby boom generation' born after WWII is reaching old age. The proportion of elderly people among decedents is also rising; in Belgium (Flanders) the proportion of those dying aged 80 or over has recently reached $50 \%$ [3].

As death nowadays mostly follows from chronic and degenerative disease with a prolonged dying process rather than from acute infectious disease, care provision in the end stages of life has become of great interest to patients, health care workers and national health care systems. A growing body of scientific literature shows that provision of end-of-life care can vary between patients of different ages [4-11]. Older patients have been reported to have less access to specialist or palliative care and to receive adequate pain and symptom treatment less often $[4,11]$, to have life-prolonging treatment forgone more often [8,11-14], to have do not resuscitate and do not hospitalise orders more often [8,15-17], and to be excluded from decision making more often $[11,18,19]$. Also, research has found that physicians and patients' family are less inclined to continue or intensify end-of-life treatment in older than in younger patients $[4,20,21]$. Patients themselves may also base decisions concerning their treatment partly on whether they have lived a long and fulfilling life $[11,14,20,22]$. These findings thus indicate significant differences or inequalities between different ages when it comes to end-of-life care and decision making. This is of great importance to health care policy makers as it may imply inequitable distribution of scarce medical resources [15,23].

So, elderly patients are generally viewed as being more vulnerable to exclusion of due care. Many opponents of legalised euthanasia warn of a 'slippery slope' towards more unethical practice among vulnerable patient groups such as older patients. These critics predict a rise in life ending without explicit request from the patient in general, and especially in elderly patient groups, in countries where euthanasia is legally regulated $[24,25]$.

In this report we investigate age-related disparities in end-of-life decisions (ELDs) with a possible or certain life shortening effect in Flanders, Belgium in 2007. The studied decisions are intensified drug administration for pain and other symptoms in doses with life shortening as possible effect, decisions to withdraw or withhold potentially life-prolonging treatment and physician-assisted dying ie the prescribing, supplying or administering of lethal drugs (ie euthanasia, physician-assisted suicide and life ending acts without explicit patient request). Belgium is one of only three countries in the world where euthanasia is legal (since 2002) under strict conditions [26]. In order to establish whether the 'slippery slope' argument holds true, particularly for the supposedly vulnerable old, data presented from the 2007 survey will be supplemented where necessary with data from an identical survey conducted in 1998, before the euthanasia law was passed. We pose the following research questions: 1) are there differences in 2007 in the incidence of the various end-of-life decisions across age groups 2) what are the incidence shifts between 1998 and 2007 in the different age groups 3) what is the preceding decision making process and 4) does the formulation and granting of euthanasia requests differ in incidence across age groups.

\section{Method}

\section{Study design}

We performed a death certificate survey in Flanders, the Flemish-speaking half of Belgium which has about six million inhabitants and approximately 55,000 deaths per year. This study was identical to a study performed in 1998 [27]. A stratified random sample of deaths was drawn by the central administration authority for death certificates, the Flemish Agency for Care and Health. All deaths between June $1^{\text {st }} 2007$ and November $30^{\text {th }} 2007$ of Belgian residents aged one year or older were first assigned to one of four strata based on the underlying cause of death, as indicated on the death certificate, and the estimated corresponding likelihood of an end-of-life decision. Sampling fractions for each stratum increased with this likelihood. Such disproportionate sampling was not done in 1998. This resulted in a sample of 6,927 deaths, about $25 \%$ of all deaths in the studied months and about $12 \%$ of all deaths in 2007 .

Every certifying physician was sent a five-page questionnaire for a maximum of five cases, with at most three reminders in cases of non-response. A lawyer was involved in the mailing procedure as intermediary between responding physicians, researchers and the Flemish Agency for Care and Health to guarantee that completed questionnaires could never be linked to a particular patient or physician. Only coded patient information from the death certificates was linked to the corresponding completed questionnaires. By guaranteeing anonymity for physicians the potential risk of social desirability bias was decreased. After data collection a one-page questionnaire was mailed to all non-responding physicians asking for the reasons for not participating. The study design, sampling and mailing procedure are described in detail elsewhere [28].

Of the 6,927 questionnaires mailed to physicians in 2007, 3,623 were returned. From the non-response analyses we found that response was not possible for 725 deaths (because the physician had changed workplace 
and did not have access to the patient's medical file, because the patient could not be identified, because the physician was not the treating physician and did not know who this was or because the questionnaire had never reached the physician). The response rate was $58.4 \%$ (3,623/6,202 eligible cases). The response rate in 1998 was $48.1 \%(1925 / 3999)$.

\section{Questionnaire}

The 2007 questionnaire was identical to the one used in 1998 [27] and was validated through testing by a panel of physicians. It first asked whether death had been sudden and unexpected. If this question was answered negatively (and hence an end-of-life decision prior to death would not be precluded) the physician was asked whether he/she had: 1) withheld or withdrawn medical treatment taking into account (NTD) or explicitly intending (NTD+) the hastening of the patient's death 2) intensified the alleviation of pain and/or other symptoms with drugs taking into account (APS) or co-intending (APS+) the possible hastening of death and 3) administered, supplied, or prescribed drugs with the explicit intention of hastening death. If in the latter case the drugs had been administered by someone other than the patient at the patient's explicit request or prescribed/ supplied and self-administered, it was classified as euthanasia or physician-assisted suicide (EAS). If there had been no explicit request from the patient, the act was classified as a life ending act - by administration of drugs - without explicit patient request (LAWER). An end-of-life decision is thus defined as a medical decision at the end of a patient's life that has a potential or certain life shortening effect.

In many cases more than one end-of-life decision can be made in relation to the same patient. Because asking the same questions about the decision making process preceding every ELD made would overburden the respondent, we asked only about decision making exclusively for the most important decision. We defined this as the decision with the most explicit life shortening intention and in case of two decisions with similar life shortening intention, administering drugs prevailed over withholding or withdrawing treatment. Questions about the preceding decision making process were: whether the decision had been discussed with the patient, family and other professional caregivers and whether there had been a request by the patient. If no discussion had taken place with the patient, physicians were asked whether the patient was deemed lacking in capacity and whether the patient had ever, implicitly or explicitly, expressed a wish for life ending. The questionnaire also asked about the reasons for coming to the most important decision. Independently of whether an end-of-life decision had been made, an additional question was posed whether the patient had made a request for euthanasia that had not been granted and if so, for what reasons. Demographic and clinical patient data were obtained from the death certificates, and linked anonymously after data collection.

\section{Analysis}

The response samples were corrected for disproportionate stratification (2007) and adjusted to be representative of all deaths for each year (1998 and 2007) for age, sex, place and cause of death. We selected the non-sudden deaths as denominator in all analyses. Euthanasia and assisted suicide were grouped together given that there were only five assisted suicide cases. For incidence estimates and comparison of estimates between 1998 and 2007, all ELDs made in each patient were included in the analysis. The most important ELD was taken into account in the analysis of the decision making process because questions about decision making were only posed for the most important ELD. Bivariate percentages were calculated and logistic regressions were performed to determine bivariate and multivariate p-values (age entered as categorical variable). A p-value of $<0.05$ is considered to indicate statistical significance. All statistical analyses were done using SPSS 17.0.

\section{Results}

\section{Socio-demographic and clinical characteristics}

In Flanders, Belgium in 2007 68.1\% of deaths were deemed non-sudden and expected (data not shown). Decedents older than 80 years are more often female, widowed and with lower levels of education than are younger decedents (Table 1). They are also more likely to die in a care home as opposed to in hospital and less often from cancer than their younger counterparts. Instead, death at old age is associated with more cardiovascular and respiratory disease.

\section{Incidence of ELDs in 2007 and comparison with 1998}

In Table 2 the incidence of the various ELDs across age groups is given. For intensified alleviation of pain and symptoms (APS) a decrease in incidence with age is noticeable in bivariate analysis $(\mathrm{p}>.001)$. There is also a negative association with age $(\mathrm{p}=.017)$ in relation to pain and symptom alleviation with life shortening cointention (APS+). The associations disappear however in multivariate analysis under the influence of cause of death (not in table). Non-treatment decision (NTD) incidence in 2007 remains relatively stable across age groups at a little over $50 \%$ and no significant association with age is found. The same applies when life shortening is explicitly intended (NTD+). For euthanasia and assisted suicide (EAS) we see a bivariately significant decrease in rate with increasing age, but this does not hold in 
Table 1 Socio-demographic and clinical characteristics of non-sudden deaths 2007 (weighted \%)

\begin{tabular}{|c|c|c|c|c|c|}
\hline & \multirow[b]{2}{*}{ Total } & \multicolumn{3}{|c|}{ Age (yrs) } & \multirow[t]{2}{*}{$\mathrm{p}$-value $\left(\mathrm{Chi}^{2}\right)$} \\
\hline & & -65 & $65-79$ & $80+$ & \\
\hline N (unweighted) & 2729 & 550 & 972 & 1207 & \\
\hline \% In sample (weighted) & 100 & 15,8 & 32,5 & 51,7 & \\
\hline Sex & & & & & $<0,001$ \\
\hline male & 47,3 & 54,5 & 59,4 & 37,6 & \\
\hline female & 52,7 & 45,5 & 40,6 & 62,4 & \\
\hline Marital status & & & & & $<0,001$ \\
\hline married & 46,3 & 67,0 & 62,1 & 30,0 & \\
\hline unmarried/divorced & 14,3 & 28,1 & 14,4 & 10,0 & \\
\hline widowed & 39,4 & 4,9 & 23,4 & 60,0 & \\
\hline Education & & & & & $<0,001$ \\
\hline none or primary & 36,0 & 15,2 & 31,6 & 45,1 & \\
\hline lower secondary & 18,5 & 20,6 & 23,7 & 14,6 & \\
\hline higher secondary/higher & 17,8 & 38,3 & 19,6 & 10,5 & \\
\hline unknown & 27,6 & 26,0 & 25,1 & 29,8 & \\
\hline Cause of death & & & & & $<0,001$ \\
\hline cancer & 35,4 & 63,2 & 46,4 & 20,1 & \\
\hline cardiovascular & 29,2 & 15,2 & 20,7 & 38,7 & \\
\hline respiratory & 12,0 & 4,6 & 11,6 & 14,5 & \\
\hline neurological & 4,1 & 3,6 & 4,7 & 3,9 & \\
\hline other & 19,3 & 13,4 & 16,5 & 22,8 & \\
\hline Place of death & & & & & $<0,001$ \\
\hline hospital & 51,2 & 62,6 & 60,3 & 41,9 & \\
\hline at home & 20,9 & 30,7 & 24,7 & 15,5 & \\
\hline care home & 25,2 & 1,5 & 12,1 & 40,6 & \\
\hline other & 2,8 & 5,2 & 2,9 & 2,0 & \\
\hline
\end{tabular}

multivariate analysis on the count of cause and place of death (not in table). Lastly, the incidence of life ending without explicit patient request (LAWER) is not associated with age and amounts to $1.2 \%$ and $3.8 \%$ of nonsudden deaths.

Figure 1 presents the Table 2 percentages graphically, supplemented by 1998 data, and Table 3 shows the multivariate odds ratios for the various ELDs by age groups between 1998 and 2007. Intensified alleviation of pain and symptoms (APS) is consistently more likely to be performed in 2007 than in 1998, in all age groups. With life shortening co-intended (APS+) the reverse picture emerges: this decision is in every age group less likely in 2007 than in 1998. Non-treatment decisions (NTD) are more likely in 2007 for the age groups 6579 years and $80+$ years than in 1998. Decisions not to treat with an explicit life shortening intention (NTD+) are less likely in 2007 than in 1998 for the oldest age group (80+ years). In the age group 65-79 years euthanasia and assisted suicide (EAS) are 2.4 times more likely to occur in 2007 than in 1998; for other age groups the odds ratio is not statistically significant. As concerns life ending acts without explicit request (LAWER), patients younger than 65 years were 5.9 times less likely to undergo this decision in 2007 than in 1998 and patients aged 65-79 1.9 times less likely. Patients aged 80 or over did not have a significantly different chance of life ending without request than in 1998.

\section{Decision making process of ELDs}

Concerning the process of decision making where intensified alleviation of pain and other symptoms (APS) was the most important decision, younger patients are more often included in the discussion and more often formulate an explicit request than do older patients (Table 4).

Table 2 ELD incidence 2007 by age groups, non-sudden deaths (weighted \%)

\begin{tabular}{|c|c|c|c|c|c|c|c|c|c|c|}
\hline & \multicolumn{8}{|c|}{ Patient age (yrs) } & \multicolumn{2}{|c|}{$p$-value* } \\
\hline & -45 & $45-64$ & $65-69$ & $70-74$ & $75-79$ & $80-84$ & $85-89$ & $90+$ & biv. & multiv. \\
\hline & $\overline{n=76}$ & $\overline{n=474}$ & $\overline{n=217}$ & $\overline{n=293}$ & $\overline{n=462}$ & $n=483$ & $\overline{n=391}$ & $\overline{n=333}$ & & \\
\hline APS & 74,4 & 61,5 & 59,0 & 62,8 & 50,4 & 50,5 & 46,7 & 46,5 & $<0.001$ & 0.119 \\
\hline APS+ & 18,6 & 13,4 & 13,1 & 15,5 & 12,4 & 12,5 & 9,6 & 6,8 & 0.017 & 0.504 \\
\hline NTD & 54,4 & 53,8 & 53,2 & 56,6 & 50,1 & 52,4 & 50,1 & 51,7 & 0.800 & 0.761 \\
\hline NTD+ & 21,1 & 18,7 & 19,8 & 17,9 & 21,0 & 15,9 & 15,9 & 13,0 & 0.107 & 0.215 \\
\hline EAS & 6,2 & 6,8 & 4,8 & 4,5 & 3,0 & 2,5 & 0,5 & 0,1 & $<0.001$ & 0.359 \\
\hline LAWER & 2,8 & 1,2 & 3,8 & 3,0 & 3,0 & 3,1 & 3,4 & 1,5 & 0.435 & 0.671 \\
\hline
\end{tabular}

Unweighted number of cases, weighted percentages.

*p-values calculated by logistic regression (age entered as categorical variable). Multivariate regression with confounders sex, marital status, cause of death, place of death (no interaction effects); educational attainment not featured in multivariate model due to the large number of missings.

ELD: end-of-life decision; APS: intensified alleviation of pain and other symptoms; APS+: intensified alleviation of pain and other symptoms co-intending life shortening; NTD: non-treatment decisions; NTD+: non-treatment decisions explicitly intending life shortening; EAS: euthanasia and physician-assisted suicide; LAWER: life ending acts without explicit patient request. 


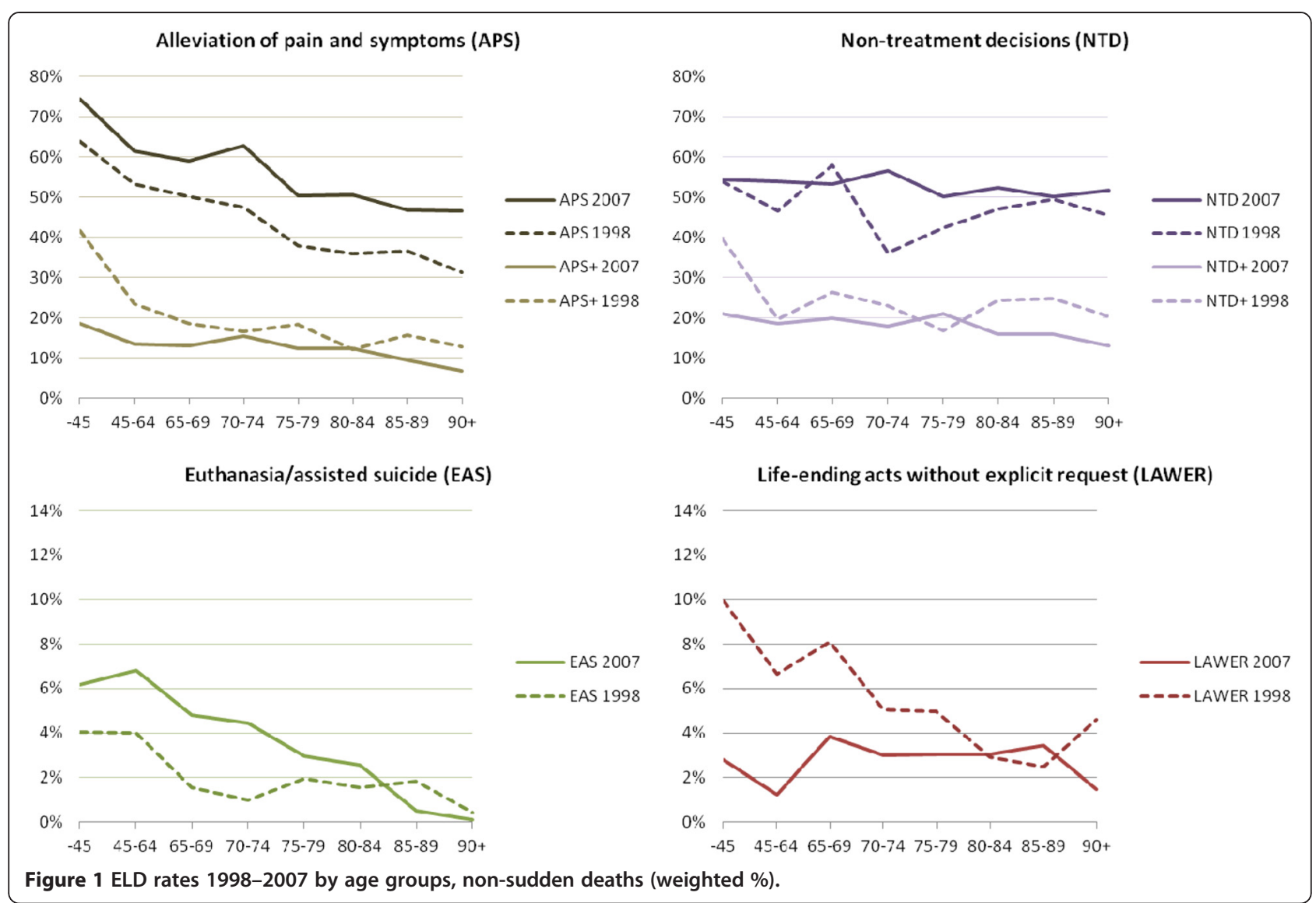

This association between age, inclusion in discussion and request rate remains significant after multivariate controlling for confounders. The same multivariate association is found in discussion with the patient about intensifying pain and symptom treatment with life shortening co-intention (APS+): $70 \%$ of patients younger than 65 years are included compared with 19\% of patients older than 80 years. Also, for intensified pain and symptom treatment older patients were more often deemed lacking in capacity. For all other end-of-life decisions the proportion of patients lacking in capacity did not differ significantly across age groups, though a higher rate of incompetence is found in older patient groups. Palliative care (PC) specialists were more often consulted in relation to younger patients than to the oldest patients for intensified pain and symptom alleviation.

Table 3 Multivariate ORs (95\% Cl) 2007 vs. 1998 for ELD incidences by age groups (weighted)*

\begin{tabular}{|c|c|c|c|c|}
\hline & & Patient age (yrs) & & all ages \\
\hline & -65 & $65-79$ & $80+$ & \\
\hline$\overline{A P S}$ & $1,46(1,01-2,11)$ & $1,57(1,23-2,01)$ & $1,83(1,49-2,25)$ & $1,66(1,44-1,91)$ \\
\hline APS+ & $0,45(0,29-0,69)$ & $0,71(0,51-0,97)$ & $0,70(0,52-0,95)$ & $0,64(0,53-0,78)$ \\
\hline NTD & $1,25(0,88-1,76)$ & $1,40(1,11-1,77)$ & $1,23(1,01-1,50)$ & $1,30(1,13-1,49)$ \\
\hline NTD+ & $0,74(0,49-1,14)$ & $0,91(0,68-1,21)$ & $0,60(0,47-0,77)$ & $0,73(0,62-0,87)$ \\
\hline EAS & $1,63(0,72-3,72)$ & $2,42(1,04-5,65)$ & $0,86(0,36-2,06)$ & $1,60(0,99-2,58)$ \\
\hline LAWER & $0,17(0,06-0,47)$ & $0,52(0,30-0,93)$ & $0,87(0,49-1,54)$ & $0,56(0,39-0,79)$ \\
\hline
\end{tabular}

*1998 is the reference year. Odds ratios (ORs) and $95 \%$ confidence intervals (Cl) in bold indicate statistically significant differences between 1998 and 2007 (multivariate logistic regression with confounders sex, marital status, cause of death, place of death - no interaction effects; educational attainment not featured in multivariate model due to the large number of missings).

ELD: end-of-life decision; APS: intensified alleviation of pain and other symptoms; APS+: intensified alleviation of pain and other symptoms co-intending life shortening; NTD: non-treatment decisions; NTD+: non-treatment decisions explicitly intending life shortening; EAS: euthanasia and physician-assisted suicide; LAWER: life ending acts without explicit patient request. 
Table 4 Decision making with patient, family and caregivers 2007 by ELD and age groups (weighted \%)

\begin{tabular}{|c|c|c|c|c|c|c|c|c|c|c|c|c|c|c|c|c|c|c|}
\hline Most important ELD & & APS & & & APS+ & & & NTD & & & NTD+ & & & EAS & & & LAWER & \\
\hline Patient age (yrs) & -65 & $65-79$ & $80+$ & -65 & $65-79$ & $80+$ & -65 & $65-79$ & $80+$ & -65 & $65-79$ & $80+$ & -65 & $65-79$ & $80+$ & -65 & $65-79$ & $80+$ \\
\hline N (unweighted) & 288 & 461 & 500 & 40 & 71 & 55 & 93 & 190 & $\overline{285}$ & $\overline{63}$ & 121 & $\overline{138}$ & $\overline{51}$ & 64 & 27 & 10 & 28 & 28 \\
\hline discussed with patient & $\underline{41}$ & $\underline{26}$ & $\underline{17}$ & $\underline{70}$ & $\underline{47}$ & 19 & 25 & 24 & 17 & 27 & 24 & 24 & 100 & 100 & 100 & 33 & 24 & 19 \\
\hline discussed and explicit request by patient & $\underline{29}$ & $\underline{19}$ & $\underline{11}$ & 57 & 30 & 15 & 11 & 10 & 10 & 14 & 10 & 15 & 100 & 100 & 100 & 0 & 0 & 0 \\
\hline not discussed with patient & $\underline{59}$ & $\underline{74}$ & 84 & $\underline{30}$ & $\underline{53}$ & 81 & 75 & 76 & 83 & 73 & 76 & 76 & 0 & 0 & 0 & 67 & 76 & 81 \\
\hline not discussed and patient not competent & $\underline{42}$ & $\underline{58}$ & $\underline{75}$ & $\underline{20}$ & $\underline{45}$ & $\underline{70}$ & 66 & 73 & 79 & 66 & 75 & 74 & - & - & - & 60 & 65 & 74 \\
\hline not discussed but wish stated by patient & 8 & 12 & 15 & 5 & 20 & 11 & 9 & 15 & 21 & 9 & 20 & 20 & - & - & - & 17 & 23 & 47 \\
\hline discussed with family & $\underline{54}$ & $\underline{60}$ & $\underline{53}$ & 65 & 72 & 73 & 33 & 36 & 40 & 79 & 73 & 74 & 78 & 81 & 64 & 67 & 76 & 83 \\
\hline discussed with colleague(s) & 43 & 37 & 31 & 57 & 54 & 38 & 63 & 57 & 41 & 76 & 63 & 49 & 85 & 83 & 53 & 67 & 64 & 53 \\
\hline discussed with PC specialist & $\underline{24}$ & $\underline{27}$ & $\underline{17}$ & $\underline{46}$ & $\underline{44}$ & $\underline{16}$ & $\underline{8}$ & $\underline{15}$ & $\underline{18}$ & 11 & $\underline{20}$ & $\underline{23}$ & 54 & 60 & 21 & 50 & 12 & 1 \\
\hline discussed with nurse(s) & 28 & 43 & 37 & 44 & 58 & 46 & 42 & 40 & 46 & 44 & 46 & 53 & 58 & 61 & 29 & 50 & 56 & 27 \\
\hline
\end{tabular}

Percentages in bold indicate statistically significant differences between age groups after bivariate logistic regression, $\mathrm{p}<.05$.

Underlined percentages indicate statistically significant differences between age groups after multivariate logistic regression controlling for confounders

(sex, marital status, cause of death, place of death - no interaction effects; educational attainment not featured in multivariate model due to the large number of missings), $\mathrm{p}<.05$

ELD: end-of-life decision; APS: intensified alleviation of pain and other symptoms; APS+: intensified alleviation of pain and other symptoms co-intending life shortening; NTD: non-treatment decisions; NTD+: non-treatment decisions explicitly intending life shortening; EAS: euthanasia and physician-assisted suicide; LAWER: life ending acts without explicit patient request.

No significant age associations were found for inclusion of the patient in the discussion or for discussion with family or other caregivers in non-treatment decisions. The rate of discussion with colleague physicians was bivariately negatively associated with increasing age, whereas palliative care (PC) consultation was multivariately positively associated with increasing patient age: for non-treatment decisions in patients older than 80 years, the rate of PC consultation was $18 \%$ whereas the rate in younger patients was $8 \%$. The rate for NTD + rises from $11 \%$ in patients younger than 65 years to $23 \%$ in those older than 80 years. NTD + is the only type of ELD where patients aged 80 or over were significantly more often included in decision making than in 1998 (not in table).

Euthanasia and assisted suicide are by definition always discussed with the patient. No multivariate effect of age on decision making was found for these acts. Bivariately, a colleague physician is more often consulted in younger patients receiving euthanasia or assisted suicide $(85 \%$ and $83 \%)$ than in the oldest patients $(53 \%)$. There were also no multivariately controlled effects of age on decision making in life ending without request but the rate of PC consultation was bivariately significantly higher among patient under 65 years $(50 \%)$ than among patients over 65 years (12\%).

\section{Granting or rejecting euthanasia requests}

In 1998 younger patients tended to formulate a request for euthanasia more often than older patients but this finding was not significant after multivariate testing (Table 5). Also, the proportion of requests for euthanasia that were granted did not differ significantly between age groups. In 2007 the rate of euthanasia requests did differ significantly between age groups: the rate was $10.3 \%$ for patients younger than 65 years, $5.6 \%$ for patients aged 65 to 79 and $2.6 \%$ for patients aged 80 or older. Patients younger than 80 years were significantly more likely to see their request granted than those in the oldest patient group but this association did not hold after multivariate testing (principal confounder: cause of death). When examining the reasons for granting a euthanasia request, physicians indicated that 'life should not be prolonged needlessly' more often when it concerned older patients $(\mathrm{p}=0.016)$. This finding proved insignificant in multivariate analysis with other confounders $(\mathrm{p}=0.066)$. Physicians indicated having their own objections in principle as a relevant reason for rejecting a euthanasia request more often with the oldest patients (in 22\%), but this significant association also disappeared after multivariate testing.

\section{Discussion}

This study found a number of differences between age groups in end-of-life decision making. In 2007 the incidence of intensified pain and symptom treatment and also of euthanasia and assisted suicide decreased significantly with increasing age, but not after multivariate testing with a number of confounders. Comparing 2007 with 1998, decisions to intensify alleviation of pain and symptoms, not to treat, and to perform euthanasia or assisted suicide were more likely to have been made for intensified pain and symptom alleviation in all age groups, for non-treatment decisions in patients aged 65 or over and for euthanasia and assisted suicide only in the 65-79 age group. Alleviation of pain and symptoms 
Table 5 Granted and rejected euthanasia/assisted suicide (EAS) requests 1998 and 2007 by age groups (weighted \%)

\begin{tabular}{|c|c|c|c|c|c|}
\hline & & ient age & & & \\
\hline & -65 & $65-79$ & $80+$ & biv. & multiv. \\
\hline 1998 & $n=181$ & $n=408$ & $n=640$ & & \\
\hline Request for EAS & 7,6 & 4,6 & 3,9 & 0.097 & 0.326 \\
\hline granted & 53 & 32 & 35 & 0.392 & 0.909 \\
\hline rejected & 47 & 68 & 65 & & \\
\hline 2007 & $\mathrm{n}=550$ & $n=972$ & $n=1207$ & & \\
\hline Request for EAS & 10,3 & 5,6 & 2,6 & $<0.001$ & 0.034 \\
\hline granted & 63 & 64 & 38 & 0.039 & 0.296 \\
\hline rejected & 37 & 36 & 62 & & \\
\hline Reasons for granting & $(n=51)$ & $(n=64)$ & $(n=27)$ & & \\
\hline no prospect of improvement & 92 & 77 & 87 & 0.367 & 0.715 \\
\hline request/wish of the patient & 89 & 94 & 100 & 0.736 & 0.465 \\
\hline severe symptoms (excl. pain) & 81 & 67 & 71 & 0.612 & 0.803 \\
\hline severe pain & 69 & 57 & 50 & 0.508 & 0.702 \\
\hline loss of dignity & 50 & 57 & 43 & 0.751 & 0.675 \\
\hline low expected life quality & 46 & 61 & 64 & 0.379 & 0.478 \\
\hline expected further suffering & 42 & 57 & 71 & 0.239 & 0.170 \\
\hline life should not be prolonged needlessly & 19 & 45 & 67 & 0.016 & 0.066 \\
\hline request/wish of the family & 19 & 20 & 50 & 0.095 & 0.651 \\
\hline situation unbearable for family & 19 & 16 & 20 & 0.916 & 0.914 \\
\hline Reasons for rejecting & $(n=33)$ & $(n=27)$ & $(n=25)$ & & \\
\hline death before request granted & 60 & 47 & 32 & 0.230 & 0.548 \\
\hline patient revoked request & 20 & 12 & 17 & 0.808 & 0.994 \\
\hline no well-considered request & 7 & 11 & 13 & 0.823 & 0.494 \\
\hline fear for legal consequences & 7 & 18 & 0 & 0.104 & $>0.999$ \\
\hline suffering was not unbearable & 7 & 0 & 17 & 0.155 & 0.485 \\
\hline principle objections & 0 & 0 & 22 & 0.022 & 0.389 \\
\hline medical condition not hopeless & 0 & 0 & 13 & 0.110 & 0.818 \\
\hline institutional policy & 0 & 0 & 13 & 0.110 & $>0.999$ \\
\hline patient was not terminally ill & 0 & 0 & 4 & 0.492 & $>0.999$ \\
\hline no voluntary request & 0 & 0 & 0 & $>0.999$ & $>0.999$ \\
\hline other reason(s) & 7 & 12 & 9 & 0.879 & 0.832 \\
\hline
\end{tabular}

Unweighted number of cases, weighted percentages.

*p-values calculated by logistic regression. Multivariate regression with confounders sex, marital status, cause of death, place of death (no interaction effects); educational attainment not featured in multivariate model due to the large number of missings.

with a co-intention to hasten death occurred less often in 2007 than in 1998 in all age groups whereas nontreatment decisions with explicitly intended life shortening were less likely only for the oldest age group and life ending without explicit request less likely only for patients younger than 80 years. As concerns decision making with the patient in 2007 this was more often done with younger patients for intensified alleviation of pain and symptoms. For such decisions a palliative care specialist was less often involved when the patient was 80 years or older while the opposite was found for non- treatment decisions. Lastly, in 2007 the rate of euthanasia requests decreased with increasing age and the oldest patients saw their request rejected more often, though this latter finding was not significant after multivariate testing.

Though the occurrence of the various ELDs in 2007 was not directly influenced by patient age, we did find a bivariate (negative) association of age with intensified pain and symptom alleviation and with euthanasia/ assisted suicide. It is well known that older patients have different socio-demographic and clinical profiles from 
younger ones, as Table 1 shows. The main diagnosis and place of death seemed to be the factors determining the likelihood of an end-of-life decision. This does not however mean that there is no problem related to age. The reality remains that older patients are less likely to receive intensified pain and symptom treatment in the context of palliative care, something which is confirmed by the higher levels of consultation of palliative care experts for younger patient groups and which is consistent with earlier studies $[8,29]$. This is probably because elderly patients die from cancer relatively infrequently and palliative care is historically provided mainly to cancer patients [30-32] as the cancer trajectory is more predictable $[2,30,33]$. Generally, policy should aim at taking away barriers to equality between ages independently of diagnosis. Patients of all ages should be entitled to the same intensity and quality of care. If provision of palliative care is expanded to patients with non-malignant diagnoses, something which is widely advocated $[30,32,33]$, the differences between age groups, and specifically the 'undertreatment' of the oldest, should disappear. This is of course assuming that the lower incidence of pain and symptom alleviation in older patients is a sign of undertreatment; hypotheses explaining the age disparity in palliative care consumption include the suggestion that pain and other symptoms are less often recognised in elderly patients $[8,21,34]$, that elderly patients are less able to report them $[16,33]$ or that they have learned to cope with long-term pain $[35,36]$. These hypotheses seem to be disproved by our data; the issue should be investigated more deeply.

As concerns euthanasia and assisted suicide, it is not possible to make qualitative/moral judgments on the effect of age on occurrence, which in our multivariate model was explained by differences between cancer and non-cancer diagnosis. What we know is that there is more acceptance of euthanasia among younger generations [37]. Our finding that older patient groups request euthanasia less often than do younger groups corroborates this. This can be related to generational effects and also to differences in educational attainment [38]. Unfortunately, the latter factor could not be included in the analysis. It is significant, however, that there is no agebased difference in the proportion of requests granted. Our study did find a bivariate relationship ie fewer requests granted in the 80+ age group than in younger groups, but this disappeared after multivariate testing again due to differences between cancer and non-cancer diagnosis. So it seems that non-cancer patients are less likely to have their request for euthanasia granted. This is not problematic per se as the Belgian euthanasia law prescribes rigorous criteria for eligibility [26], and these criteria are thought to be less easily confirmed in noncancer patients. Indeed, because legal criteria such as 'unbearable suffering' are so difficult to define in practice, cancer patients may be viewed as the 'ideal' euthanasia patient against which euthanasia requests from non-cancer patients are compared and often deemed insufficiently in accordance with the euthanasia law [39]. However, euthanasia among cancer patients may be socially more acceptable making physicians more reluctant to grant euthanasia to non-cancer patients. If this is the case then the difference between the options available to cancer and non-cancer patients becomes problematic. More research is needed to elucidate this.

One finding that is not in line with previous research $[8,12,13]$ is that the incidence of non-treatment decisions does not increase with age; if anything, our analyses show a tendency towards fewer decisions to forgo life-sustaining or life-saving treatment as age increases, particularly where the hastening of death is explicitly intended. Many studies suggest that considerations of age may come into play when deciding whether to initiate or continue treatment at the end of life, in surveys of both attitudes and actual practice [8,11-14]. In Flanders, Belgium, this phenomenon seems nonexistent or marginal at most. In past studies in Belgium (and elsewhere) using the same method we did find age differences in incidence of non-treatment decisions, but this is because we included only the most important ELD for each case $[3,27]$. When analysing cases permitting more than one ELD per case, we find no age differences in NTD incidence. Further research could study whether different types of non-treatment decisions (medication, hydration/nutrition, CPR, respiration, oncotherapy, surgery, dialysis) have divergent frequencies in various age groups.

Though age may not be a determining factor in the incidence of end-of-life decisions, it is all the more important in decision making. The older the patient, the less often he or she is involved in decision making to intensify pain and symptom alleviation, and the less likely he or she is to explicitly request it. This confirms the findings of other studies which offer relevant explanatory hypotheses of lower assertiveness or empowerment and less aspiration to autonomy in older patients $[11,18]$. Elderly patients often put all faith in the physician, who is viewed as the expert as well as the moral authority in what is perceived as a hierarchical relationship $[18,40]$. Elderly patients were in our study also more frequently found to be lacking in capacity to be involved in end-oflife decision making. As consensus continues to grow that respecting the patient's wishes is paramount in these decisions [14,15,19,32], the need for advance care planning, or at least an exploration of preferences before the patient loses capacity is thus very clear, particularly in the oldest patient groups [2,19,41]. Save for nontreatment decisions, the inclusion rate of older patients 
in end-of-life decisions has not significantly increased since 1998. Additionally, we found no accompanying higher rate of family inclusion or consultation of colleagues or nurses in decision making in older patients than there had been a decade earlier. It is thus warranted to conclude that older patients are at higher risk of paternalism. Advance care planning initiatives need to target the oldest patient population specifically.

What emerges clearly from our findings is that there is no evidence to support the slippery slope hypothesis $[24,25]$ in elderly patients, let alone in general. Life ending acts without explicit patient request have not risen in incidence since the enactment of the euthanasia law; to the contrary, LAWER incidence has decreased significantly since 1998 in the age groups below 80 years though in the oldest patients the rate has remained the same. Also elderly patients are not more at risk of LAWER than younger patients in 2007. Our findings thus do not confirm the 'slippery slope' hypothesis either in general or in elderly patients. It is, however, noteworthy that the LAWER rate has remained stagnant since 1998 in the oldest age group while it is declining in younger age groups. This may be an indication of persistent paternalism in decision making for elderly patients, and further argument for focusing advance care initiatives on the oldest. The development of the incidence of a controversial decision like LAWER in older patients needs to be closely monitored, as adverse effects could only become apparent after a longer period of legalised euthanasia.

There are a number of limitations inherent in this study. Given the length of time between the death in question and completing the questionnaire, we cannot exclude the influence of memory bias in the reporting physicians. Also, our survey includes only the perspective of the treating physicians and not those of relatives or other caregivers. The more than $40 \%$ non-response rate may have generated bias in the results, although the data were weighted to correct for this. As our study depends on a conceptualisation of reality, the classification scheme of ELDs as approximation may not fully reflect actual practices and ignore the complexity of end-of-life decision making. Furthermore, although we have information on the process of decision making, we do not know what the discussion outcomes were. Finally, we could not include in the analyses the patient's educational attainment as confounder to age due to the high proportion of missing cases, although this may be an important determining factor in end-of-life decision making.

\section{Conclusion}

We conclude that age is not a determining factor in the rate of end-of-life decisions, but plays a role in the preceding decision making process. Whereas the rates of non-treatment decisions and life ending without request do not differ between age groups, those of intensified pain and symptom alleviation and euthanasia/assisted suicide requests do but are determined predominantly by diagnosis ie cancer/non-cancer. Conversely, patient involvement in decision making ís determined by patient age independently of other factors and this suggests the need for a focus on advance care planning initiatives for elderly patients. Comparison with data from before Belgian euthanasia regulation yielded no evidence of a 'slippery slope' as fewer LAWER cases were reported since the euthanasia law. Nonetheless this needs to be monitored closely in the future.

\section{Competing interests}

The authors declare that they have no competing interests.

\section{Authors' contributions}

$K C, J B$ and $L D$ were involved in the conception and design of the survey. $\mathrm{KC}$ carried out the data collection and the analysis of the results. All authors were involved in the interpretation of the results. KC and JR drafted the manuscript and all other authors critically revised it. All authors gave final approval for the manuscript.

\section{Acknowledgments}

We thank Herwin De Kind, Anne Kongs, the team of the Flemish Agency for Care and Health, lawyer Wim De Brock and Geert Pousset for their cooperation in the data collection. The Belgian National Disciplinary Board of Physicians approved and supported the study. Especially we thank the thousands of physicians who provided the study data.

Funding bodies are the Belgian Federal Science Policy Office (BELSPO) and the Institute for the Promotion of Innovation by Science and Technology Flanders (IWT-Vlaanderen). KC is Postdoctoral Fellow of the Research Foundation - Flanders (FWO).

\section{Author details}

${ }^{1}$ End-of-life Care Research Group, Ghent University \& Vrije Universiteit Brussel, Laarbeeklaan 103, Brussels 1090, Belgium. ${ }^{2}$ Department of Public and Occupational Health, EMGO Institute for Health and Care Research, VU University Medical Centre, Amsterdam, the Netherlands.

Received: 18 October 2011 Accepted: 12 April 2012 Published: 18 June 2012

\section{References}

1. Seale C: Changing patterns of death and dying. Soc Sci Med 2000, 51:917-930.

2. Lynn J: Living long in fragile health: the new demographics shape end of life care: The Hastings Center report; 2005. Spec No:S14-8.

3. Chambaere K, Bilsen J, Cohen J, Onwuteaka-Philipsen BD, Mortier F, Deliens L: Trends in medical end-of-life decision making in Flanders, Belgium 1998-2001-2007. Med Decis Making 2011, 31:500-510.

4. Happ MB, Capezuti E, Strumpf NE, Wagner L, Cunningham S, Evans L, Maislin G: Advance care planning and end-of-life care for hospitalized nursing home residents. J Am Geriatr Soc 2002, 50:829-835.

5. Green CR, Hart-Johnson T: Cancer pain: an age-based analysis. Pain Med 2010, 11:1525-1536.

6. Burt J, Raine R: The effect of age on referral to and use of specialist palliative care services in adult cancer patients: a systematic review. Age Ageing 2006, 35:469-476.

7. Hamel MB, Teno JM, Goldman L, Lynn J, Davis RB, Galanos AN, Desbiens N, Connors AF, Wenger N, Phillips RS: Patient age and decisions to withhold life-sustaining treatments from seriously ill, hospitalized adults. SUPPORT Investigators. Study to Understand Prognoses and Preferences for Outcomes and Risks of Treatment. Ann Intern Med 1999, 130:116-125. 
8. Formiga F, López-Soto A, Navarro M, Riera-Mestre A, Bosch X, Pujol R: Hospital deaths of people aged 90 and over: end-of-life palliative care management. Gerontology 2008, 54:148-152.

9. Duffin C: Health care is still age-biased. Nurs Older People 2008, 20:9.

10. Gielen B, Remacle A, Mertens R: Patterns of health care use and expenditure during the last 6 months of life in Belgium: differences between age categories in cancer and non-cancer patients. Health Policy (Amsterdam, Netherlands) 2010, 97:53-61.

11. Maddison AR, Asada Y, Urquhart R: Inequity in access to cancer care: a review of the Canadian literature. Cancer Causes Control 2011, 22:359-366.

12. Bosshard G, Nilstun T, Bilsen J, Norup M, Miccinesi G, van Delden JJM, Faisst $K$, van der Heide A: Forgoing treatment at the end of life in 6 European countries. Arch Intern Med 2005, 165:401-407.

13. Vrakking $A M$, van der Heide A, van Delden JJM, Looman CWN, Visser MH, van der Maas PJ: Medical decision-making for seriously ill non-elderly and elderly patients. Health Policy (Amsterdam, Netherlands) 2005 75:40-48.

14. Visser A, Dijkstra GJ, Kuiper D, de Jong PE, Franssen CFM, Gansevoort RT, Izaks GJ, Jager KJ, Reijneveld SA: Accepting or declining dialysis: considerations taken into account by elderly patients with end-stage renal disease. J Nephrol 2009, 22:794-799.

15. Gordon M: Ethical challenges in end-of-life therapies in the elderly. Drugs Aging 2002, 19:321-329.

16. Lamberg JL, Person CJ, Kiely DK, Mitchell SL: Decisions to hospitalize nursing home residents dying with advanced dementia. J Am Geriatr SoC 2005, 53:1396-1401

17. Nathens AB, Rivara FP, Wang J, Mackenzie EJ, Jurkovich GJ: Variation in the rates of do not resuscitate orders after major trauma and the impact of intensive care unit environment. J Trauma 2008, 64:81-88. discussion 88-91.

18. Winzelberg GS, Hanson LC, Tulsky JA: Beyond autonomy: diversifying end-of-life decision-making approaches to serve patients and families. J Am Geriatr Soc 2005, 53:1046-1050.

19. Lorenz KA, Rosenfeld K, Wenger N: Quality indicators for palliative and end-of-life care in vulnerable elders. J Am Geriatr Soc 2007, 55(Suppl 2): S318-S326.

20. Zikmund-Fisher BJ, Lacey HP, Fagerlin A: The potential impact of decision role and patient age on end-of-life treatment decision making. J Med Ethics 2008, 34:327-331.

21. Wakunami M, Kawabata H, Murakami M, Maezawa M: Families' acceptance of near death: a qualitative study of the process for introducing end-of-life care. Geriatr Gerontol Int 2009, 9:140-147.

22. Rietjens JAC, van der Heide A, Voogt E, Onwuteaka-Philipsen BD, van der Maas PJ, van der Wal G: Striving for quality or length at the end-of-life: attitudes of the Dutch general public. Patient Educ Couns 2005, 59:158-163.

23. Pedersen R, Nortvedt $P$, Nordhaug M, Slettebø A, Grøthe KH, Kirkevold M, Brinchmann BS, Andersen B: In quest of justice? Clinical prioritisation in healthcare for the aged. J Med Ethics 2008, 34:230-235.

24. Lesser H: Should it be legal to assist suicide? J Eval Clin Pract 2010, 16:330-334.

25. George RJD, Finlay IG, Jeffrey D: Legalised euthanasia will violate the rights of vulnerable patients. BMJ (Clinical research ed.) 2005, 331:684-685

26. Belgian Official Collection of the Laws: Law concerning euthanasia - June 22, 2002 [Dutch]. 2002

27. Deliens L, Mortier F, Bilsen J, Cosyns M, Vander Stichele R, Vanoverloop J, Ingels K: End-of-life decisions in medical practice in Flanders, Belgium: a nationwide survey. Lancet 2000, 356:1806-1811.

28. Chambaere K, Bilsen J, Cohen J, Pousset G, Onwuteaka-Philipsen B, Mortier F, Deliens L: A post-mortem survey on end-of-life decisions using a representative sample of death certificates in Flanders, Belgium: research protocol. BMC Publ Health 2008, 8:299.

29. Drieskens K, Bilsen J, Van Den Block L, Deschepper R, Bauwens S, Distelmans W, Deliens L: Characteristics of referral to a multidisciplinary palliative home care team. J Palliat Care 2008, 24:162-166.

30. Lunney JR, Lynn J, Foley DJ, Lipson S, Guralnik JM: Patterns of functional decline at the end of life. JAMA 2003, 289:2387-2392.

31. Lunney JR, Lynn J, Hogan C: Profiles of older medicare decedents. J Am Geriatr Soc 2002, 50:1108-1112.

32. Field D, Addington-Hall J: Extending specialist palliative care to all? Soc Sci Med 1999, 48:1271-1280
33. Eng C: Future consideration for improving end-of-life care for older persons: Program of All-inclusive Care for the Elderly (PACE). J Palliat Med 2002, 5:305-310.

34. Reynolds KS, Hanson LC, Henderson M, Steinhauser KE: End-of-life care in nursing home settings: do race or age matter? Palliat Support Care 2008, 6:21-27.

35. Hall S, Longhurst S, Higginson I: Living and dying with dignity: a qualitative study of the views of older people in nursing homes. Age Ageing 2009, 38:411-416.

36. Lundh Hagelin C, Seiger A, Fürst CJ: Quality of life in terminal care--with special reference to age, gender and marital status. Support Care Cancer 2006, 14:320-328.

37. Cohen J, Marcoux I, Bilsen J, Deboosere P, van der Wal G, Deliens L: European public acceptance of euthanasia: socio-demographic and cultural factors associated with the acceptance of euthanasia in 33 European countries. Soc Sci Med 2006, 63:743-756.

38. Onwuteaka-Philipsen BD, Rurup ML, Pasman HRW, van der Heide A: The last phase of life: who requests and who receives euthanasia or physician-assisted suicide? Medical care 2010, 48:596-603.

39. Norwood F: The maintenance of life: preventing social death through euthanasia talk and end-of-life care: lessons from the Netherlands. Durham: Carolina Academic Press; 2009:294.

40. Rurup ML, Onwuteaka-Philipsen BD, van der Heide A, van der Wal G, Deeg DJH: Frequency and determinants of advance directives concerning end-of-life care in The Netherlands. Soc Sci Med 2006, 62:1552-1563.

41. Davies E, Higginson IJ: Better palliative care for older people. Copenhagen: World Health Organisation (WHO); 2004:40.

doi:10.1186/1471-2458-12-447

Cite this article as: Chambaere et al.: Age-based disparities in end-of-life decisions in Belgium: a population-based death certificate survey. BMC Public Health 2012 12:447.

\section{Submit your next manuscript to BioMed Central and take full advantage of:}

- Convenient online submission

- Thorough peer review

- No space constraints or color figure charges

- Immediate publication on acceptance

- Inclusion in PubMed, CAS, Scopus and Google Scholar

- Research which is freely available for redistribution

Submit your manuscript at www.biomedcentral.com/submit
C Biomed Central 